\title{
A novel de novo mutation involving the MLL2 gene in a Kabuki syndrome patient presenting with seizures
}

\author{
Can Ebru Bekircan-Kurt ${ }^{1}$, Pelin Özlem Şimşek-Kiper ${ }^{2}$, Koray Boduroğlu ${ }^{2}$, Neşe Dericioğlu ${ }^{1}$ \\ ${ }^{1}$ Department of Neurology and ${ }^{2}$ Division of Pediatric Genetics, Department of Pediatrics, Hacettepe University Faculty of \\ Medicine, Ankara, Turkey. E-mail: nesedericioglu@yahoo.com \\ Received: 19 February 2015, Revised: 29 July 2015, Accepted: 19 August 2015
}

SUMMARY: Bekircan-Kurt CE, Şimsek-Kiper PÖ, Boduroğlu K, Dericioğlu N. A novel de novo mutation involving the MLL2 gene in a Kabuki syndrome patient presenting with seizures. Turk J Pediatr 2016; 58: 97-100.

Kabuki syndrome is a rare multiple congenital anomaly disorder. Although mental retardation is one of the main features, various neurological symptoms such as hypotonia and seizures can occur. Here we report on a 18-year-old Turkish male patient who was diagnosed previously as Kabuki syndrome. Molecular genetic analysis showed a novel de novo heterozygous mutation (c.12964C>T [p.Gln4322*] ) in the MLL2 gene, that leads to the synthesis of a truncated protein. The aim of the present report is to increase the awareness of Kabuki Syndrome among adult neurologists and to present a previously unreported non-sense mutation in the MLL2 gene.

Key words: Kabuki syndrome, epilepsy, EEG, MLL2, novel genetic mutation.

Kabuki syndrome (KS; OMIM 147920) is a mental retardation-malformation syndrome characterized by a peculiar face that is characterized by eversion of the lower lateral lids, arched eye brows with sparse or onethird dispersed lateral, depressed nasal tip and prominent ears; skeletal anomalies including brachydactyly and spinal deformity; dermatoglyphic abnormalities including: increased digital ulnar loop, presence of fingertip pads; mild to moderate mental retardation; and postnatal growth deficiency. This syndrome was first described in 1981 by Niikawa et al. ${ }^{1}$ and Kuroki et $\mathrm{al}^{2}$. The prevalence of $\mathrm{KS}$ in the Japanese population has been estimated as $1 / 32.000^{3}$, and more than 400 cases have been described in the literature. Although it has been first described in the Japanese population, there have been numerous reports from other ethnic groups ${ }^{4}$, including patients of Turkish descent ${ }^{5-8}$. It generally occurs because of a "de novo" mutation, involving either the myeloid/ lymphoid or mixed-lineage leukemia 2 (MLL2) gene $^{9}$ or less frequently the lysine $(\mathrm{K})$-specific demethylase 6A (KDM6A) gene ${ }^{10,11}$. Here we report on a Turkish KS patient with epilepsy carrying a novel heterozygous mutation in the MLL2 gene.

\section{Case Report}

A male patient was referred to the pediatric neurology clinic because of a complex partial seizure characterized by unresponsiveness, at the age of 9 . His past medical history included growth retardation, cryptorchidism, and hydronephrosis due to ureteropelvic stenosis. His parents were second-degree cousins; otherwise his family story was unremarkable. Physical examination revealed head circumference: $58 \mathrm{~cm}(+2 \mathrm{SD})$, body height: $173 \mathrm{~cm}\left(25-50^{\text {th }}\right.$ centile) and body weight: $99 \mathrm{~kg}$ (90-97th centile). He had long palpebral fissures, bilateral ptosis, depressed nasal tip, prominent ears, high-arched palate, bilateral fetal finger pads and short fifth finger (Fig. 1). Dysarthria and mild mental retardation (full-scale IQ score was 56) were noted in his neurological examination. His clinical findings led to the diagnosis of KS. Sequence analysis of MLL2 identified the heterozygous mutation c. $12964 \mathrm{C}>\mathrm{T}$ in exon 39. This mutation leads to a premature stop of MLL2 protein synthesis (p.Gln4322*). Both parents do not carry the mutation identified in their son.

The patient was put on carbamazepine, $600 \mathrm{mg} /$ day and during the follow-up, he reported two similar seizures per year. His electroencephalogram (EEG) depicted 
paroxysmal sharp waves over the left parietooccipital region (Fig. 2), however cranial magnetic resonance imaging (MRI) did not show any pathology. At the age of 18 years, he was admitted to the adult neurology department because of a secondary generalized tonic-clonic seizure despite treatment. Levetiracetam 2000 $\mathrm{mg} /$ day was added to his current medication and presently he is experiencing one complex partial seizure a year.

\section{Discussion}

Neurological manifestations in KS are usually characterized by hypotonia, mental retardation and epileptic seizures. Approximately 10$39 \%$ of these patients are reported to have seizures ${ }^{12,13}$, most of which are localizationrelated and have a favorable outcome ${ }^{14}, 15$. The onset of seizures can vary between neonatal period and 15 years ${ }^{13,14}$. Most of the electroencephalographic studies have revealed posteriorly located focal spikes ${ }^{16}$, despite recently reported fronto-central predominance in several patients ${ }^{15}$. Cranial MRI results can be normal ${ }^{14}$ or indicate various findings such as mild cerebral atrophy with enlarged

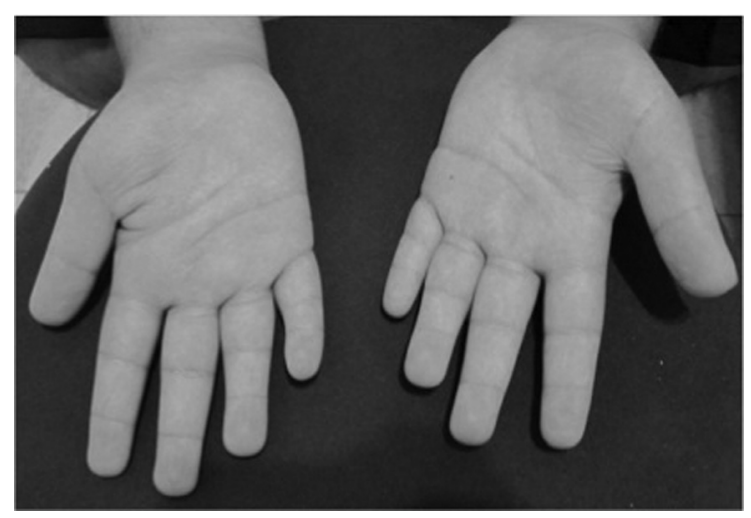

Fig. 1. The patient's fifth fingers are short bilaterally.

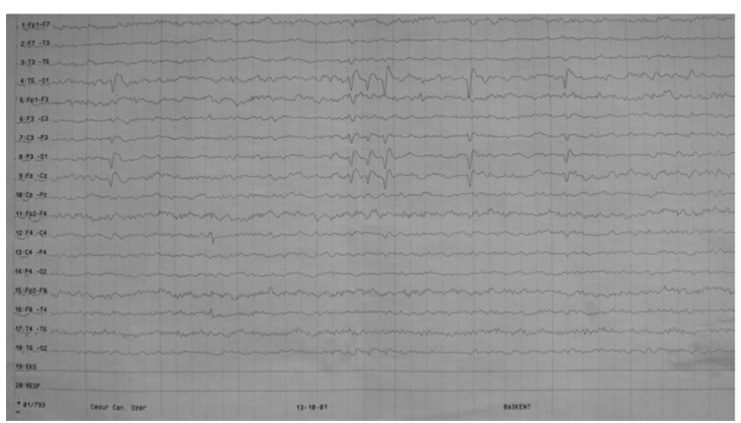

Fig. 2. EEG recording reveals paroxysmal sharp waves over the left parieto-occipital region. ventricles $^{13}$, lateral ventricular asymmetry ${ }^{15}$, corpus callosum hypoplasia ${ }^{15}$, aqueductal stenosis with hydrocephalus ${ }^{17,18}$ and arachnoid cyst $^{19}$. Apart form these abnormalities, bilateral occipital polymicrogyria18, periventricular nodular heterotopia ${ }^{6}$, bilateral perisylvian polymicrogyria ${ }^{20}$, diffuse pachygyria ${ }^{15}$, and unilateral hippocampal atrophy ${ }^{16}$ can undoubtedly be correlated with seizures. Like the majority of previous cases described in the literature, our patient also had a normal MRI, posteriorly located unilateral epileptiform discharges and very rare seizures with one or two anticonvulsant drugs. Although the mechanisms of seizures in KS are not clear, it has been hypothesized previously that both EEG abnormalities and seizures depend on diffuse brain hyperexcitability rather than abnormalities of cerebral structure ${ }^{15}$.

Kabuki syndrome was a clinical diagnosis until 2010, when $\mathrm{Ng}$ and colleagues ${ }^{21}$ identified MLL2 mutations for the first time, as the causative factor of the syndrome. Since then there have been several reports of patient series describing MLL2 mutations in $52-76 \%$ of the cases $^{9-11,22-24}$. MLL2 is a $36.3 \mathrm{~kb}$ gene located on chromosome $12 \mathrm{q} 13.12^{21}$, and encodes a protein of 5537 amino acids which is located in a multiprotein complex. The synthesized protein is a histone $\mathrm{H} 3$ lysine 4 (H3K4)-specific methyltransferase that belongs to the SET1 family of human SET-domain protein methyltransferase superfamily ${ }^{25}$. H3K4 methylation is a transcriptional activation mechanism that regulates the transcription of a set of genes involved in embryogenesis and development ${ }^{26}$. The MLL2 gene is comprised of 54 exons and its mutations lead to loss of protein function and therefore repressed transcription of a variety of developmental genes, thus causing multiple organ involvement and characteristic phenotype of the syndrome. Mutations can be observed throughout the gene, however, a great majority of them are located in exons 39 and 48, 23. Most mutations of the gene are nonsense, leading to formation of a truncated protein. Other mutations such as frameshift, missense and splice site, together with small duplications have also been described ${ }^{22,23}$. Exon 39 contains several regions that encode long polyglutamine tracts suggesting the presence of a mutational hot spot, which could explain the high rate of 
mutations in this exon. About 300 mutations have been demonstrated in MLL2 gene so far $^{11}$. The mutation identified in the present patient which leads to a truncated protein and thus most likely to haploinsufficiency of MLL2 has not yet been described in the literature. Therefore the present patient adds another novel mutation to the previous 45 mutations detected in exon $39^{24}$.

In conclusion, Kabuki syndrome is one of the most common causes of developmental delay, which is characterized by peculiar facial features, multiple organ involvement, mental retardation and seizures in some patients. It is not clear why cranial imaging findings can be so heterogeneous in KS. Further studies are needed to unravel the mechanisms of epileptogenesis, especially in patients with normal or nonspecific imaging results. As physicians' awareness of the syndrome increases, more patients are likely to be diagnosed.

\section{Acknowledgments}

We would like to thank to our patient and his family for their valuable participation, and Prof. Dr. Bernd Wollnik from Institut für Humangenetik, Uniklinik Köln for the molecular genetic analysis.

\section{REFERENCES}

1. Niikawa N, Matsuura N, Fukushima Y, Ohsawa T, Kajii T. Kabuki make-up syndrome: a syndrome of mental retardation, unusual facies, large and protruding ears, and postnatal growth deficiency. J Pediatr 1981; 99: 565-569.

2. Kuroki Y, Suzuki Y, Chyo H, Hata A, Matsui I. A new malformation syndrome of long palpebral fissures, large ears, depressed nasal tip, and skeletal anomalies associated with postnatal dwarfism and mental retardation. J Pediatr 1981; 99: 570-573.

3. Niikawa N, Kuroki Y, Kajii T, et al. Kabuki make-up (Niikawa-Kuroki) syndrome: A study of 62 patients. Am J Med Genet 1988; 31: 565-589.

4. Adam MP, Hudgins L. Kabuki syndrome: A review. Clin Genet 2005; 67: 209-219.

5. Kara B, Kayserili H, Imer M, Caliskan M, Ozmen M. Quadrigeminal cistern arachnoid cyst in a patient with kabuki syndrome. Pediatr Neurol 2006; 34: 478-480.

6. Mihci E, Tacoy S, Haspolat S, Karaali K. Central nervous system abnormalities in kabuki (niikawa-kuroki) syndrome. Am J Med. Genet 2002; 111: 448-449.

7. Tekin M, Fitoz S, Arici S, Cetinkaya E, Incesulu A. Niikawa-Kuroki (Kabuki) syndrome with congenital sensorineural deafness: evidence for a wide spectrum of inner ear abnormalities. Int J Pediatr Otorhinolaryngol 2006; 70: 885-889.
8. Rosti RO, Kayserili H. Kabuki make-up syndrome with unilateral renal agenesis. Turk J Pediatr 2009; 51: 298-300.

9. Banka S, Veeramachaneni R, Reardon W, et al. How genetically heterogeneous is kabuki syndrome?: MLL2 testing in 116 patients, review and analyses of mutation and phenotypic spectrum. Eur J Hum Genet 2012; 20: 381-388.

10. Miyake N, Mizuno S, Okamoto N, et al. KDM6A point mutations cause Kabuki syndrome. Hum Mutat 2013; 34: 108-110.

11. Miyake N, Koshimizu E, Okamoto N, et al. MLL2 and KDM6A mutations in patients with Kabuki syndrome. Am J Med Genet Part A 2013; 161A: 2234-2243.

12. Schrander-Stumpel C, Meinecke P, Wilson G, et al. The Kabuki (Niikawa-Kuroki) syndrome: Further delineation of the phenotype in 29 non-japanese patients. Eur J Pediatr 1994; 153: 438-445.

13. Kawame H, Hannibal MC, Hudgins L, Pagon RA. Phenotypic spectrum and management issues in Kabuki syndrome. J Pediatr 1999; 134: 480-485.

14. Ogawa A, Yasumoto S, Tomoda Y, Ohfu M, Mitsudome A, Kuroki Y. Favorable seizure outcome in Kabuki make-up syndrome associated with epilepsy. J Child Neurol 2003; 18: 549-551.

15. Lodi M, Chifari R, Parazzini C, et al. Seizures and EEG pattern in Kabuki syndrome. Brain Dev 2010; 32: 829-834.

16. Oksanen VE, Arvio MA, Peippo MM, Valanne LK, Sainio KO. Temporo-occipital spikes: A typical EEG finding in kabuki syndrome. Pediatr Neurol 2004; 30 67-70.

17. Kasuya H, Shimizu T, Nakamura S, Takakura K. Kabuki make-up syndrome and report of a case with hydrocephalus. Childs Nerv Syst: official journal of the International Society for Pediatric Neurosurgery 1998; 14: 230-235.

18. Di Gennaro G, Condoluci C, Casali C, Ciccarelli O, Albertini G. Epilepsy and polymicrogyria in Kabuki make-up (Niikawa-Kuroki) syndrome. Pediatr Neurol 1999; 21: 566-568.

19. Chu DC, Finley SC, Young DW, Proud VK. CNS malformation in a child with Kabuki (Niikawa-Kuroki) syndrome: Report and review. Am J Med Genet 1997; 72: 205-209.

20. Powell HW, Hart PE, Sisodiya SM. Epilepsy and perisylvian polymicrogyria in a patient with kabuki syndrome. Dev Med Child Neurol 2003; 45: 841-843.

21. Ng SB, Bigham AW, Buckingham KJ, Hannibal MC, McMillin MJ, Gildersleeve HI, et al. Exome sequencing identifies mLL2 mutations as a cause of kabuki syndrome. Nat Genet 2010; 42: 790-793.

22. Li Y, Bogershausen N, Alanay Y, et al. A mutation screen in patients with kabuki syndrome. Hum Genet 2011; 130: 715-724.

23. Hannibal MC, Buckingham KJ, Ng SB, et al. Spectrum of MLL2 (ALR) mutations in 110 cases of Kabuki syndrome. Am J Med Genet Part A. 2011; 155A: 1511-1516. 
24. Makrythanasis P, van Bon BW, Steehouwer M, et al. MLL2 mutation detection in 86 patients with Kabuki syndrome: A genotype-phenotype study. Clin Genet 2013; 84: 539-545.

25. Ansari KI, Mandal SS. Mixed lineage leukemia: Roles in gene expression, hormone signaling and mRNA processing. FEBS 2010; 277: 1790-1804.

26. Dillon SC, Zhang X, Trievel RC, Cheng X. The SET-domain protein superfamily: Protein lysine methyltransferases. Genome Biol 2005; 6: 227. 